\title{
Age-Dependent Differences in Human Brain Activity Using a Face- and Location-Matching Task: An fMRI Study
}

\author{
G. Leinsinger ${ }^{a} \quad$ C. Born ${ }^{a} \quad$ T. Meindl ${ }^{a} \quad$ A.L.W. Bokde ${ }^{b} \quad$ S. Britsch ${ }^{a} \quad$ P. Lopez-Bayo ${ }^{b}$ \\ S.J. Teipel ${ }^{b}$ H.-J. Möller ${ }^{b} \quad$ H. Hampel ${ }^{b} \quad$ M.F. Reiser ${ }^{a}$ \\ ${ }^{a}$ Department for Clinical Radiology, and bementia and Neuroimaging Research Section, Alzheimer Memorial \\ Center and Geriatric Psychiatry Branch, Department of Psychiatry, University Hospital Munich, Ludwig-Maximilian \\ University, Munich, Germany
}

\author{
Key Words \\ Location-matching $\cdot$ Face-matching $\cdot$ Visual-spatial task $•$ \\ Visual pathways $\cdot \mathrm{fMR} 1$
}

\begin{abstract}
Purpose: To evaluate the differences of cortical activation patterns in young and elderly healthy subjects for object and spatial visual processing using a face- and locationmatching task. Materials and Methods: We performed a face- and a location-matching task in 15 young (mean age: $28 \pm 9$ years) and 19 elderly (mean age: $71 \pm 6$ years) subjects. Each experiment consisted of 7 blocks alternating between activation and control condition. For face matching, the subjects had to indicate whether two displayed faces were identical or different. For location matching, the subjects had to press a button whenever two objects had an identical position. For control condition, we used a perception task with abstract images. Functional imaging was performed on a 1.5-tesla scanner using an EPI sequence. $\boldsymbol{R e}$ sults: In the face-matching task, the young subjects showed bilateral (right $>$ left) activation in the occipito-temporal pathway (occipital gyrus, inferior and middle temporal gy-
\end{abstract}

G.L. and C.B. have contributed in the same way to the work as first authors.

\section{KARGER \\ Fax +41613061234 \\ E-Mail karger@karger.ch}

(c) 2007 S. Karger AG, Basel

www.karger.com
Accessible online at:

www.karger.com/dem rus). Predominantly right hemispheric activations were found in the fusiform gyrus, the right dorsolateral prefrontal cortex (inferior and middle frontal gyrus) and the superior parietal gyrus. In the elderly subjects, the activated areas in the right fronto-lateral cortex increased. An additional activated area could be found in the medial frontal gyrus (right $>$ left). In the location-matching task, young subjects presented increased bilateral (right $>$ left) activation in the superior parietal lobe and precuneus compared with face matching. The activations in the occipito-temporal pathway, in the right fronto-lateral cortex and the fusiform gyrus were similar to the activations found in the face-matching task. In the elderly subjects, we detected similar activation patterns compared to the young subjects with additional activations in the medial frontal gyrus. Conclusion: Activation patterns for object-based and spatial visual processing were established in the young and elderly healthy subjects. Differences between the elderly and young subjects could be evaluated, especially by using a face-matching task.

Copyright $\odot 2007$ S. Karger AG, Basel

\section{Introduction}

Functional magnetic resonance imaging (fMRI) has proved to be a useful tool for the noninvasive investigation of sensory, motor and cognitive processing in the

Dr. C. Born, MD

Institute for Clinical Radiology, University Hospital Munich

Ludwig-Maximilian University, Marchioninistrasse 15

DE-80336 Munich (Germany)

Tel. +49 897095 1, Fax +49 897095 3270, E-Mail christine.born@med.uni-muenchen.de 
human brain. The use of fMRI in the study of brain dysfunction associated with dementia and other neurological and psychiatric diseases has led to an increased number of fMRI examinations in elderly subjects [1-3]. For this reason, it is critical to understand how normal aging may influence fMRI results.

Therefore, visual processing pathways, especially face recognition tasks, have been studied extensively during the past few years in healthy young subjects. Neurophysiological recordings have provided evidence for the existence of localized brain areas related to facial perception and recognition $[4,5]$. Understanding how the human brain perceives and recognizes faces has become one of the most exciting and debated areas of research in cognitive neuroscience $[6,7]$. Pursuing this general goal, neuroimaging studies using fMRI have localized a set of brain areas in the human visual extrastriate cortex that respond more during the presentation of faces than to other object categories. These areas were located mainly in the middle lateral fusiform gyrus (the fusiform face area FFA, BA 37) [8], and in the inferior occipital gyrus (occipital face area OFA, BA 19) [9], with a right hemispheric predominance. These areas help in the perception and discrimination of faces. This includes the discrimination between faces and other objects (face detecting) or the discrimination between different faces. Further, they also contribute to presemantic face recognition, i.e. the discrimination between a previously seen and a novel face.

In contrast to object-based visual processing, PET studies described separate neuroanatomical locations corresponding to spatial visual processing $[10,11]$. These results demonstrated the existence of dissociable regions of the human visual extrastriate cortex. The spatial location tasks activated a distinct region within the lateral superior parietal cortex.

The previously reported results obtained with the healthy controls demonstrated that the activation pattern for the face- and location-matching task differentially activated the ventral and dorsal pathways of the visual system, respectively. Comparison between the face- and location-matching tasks found regions in the visual system that modulate their activation depending if the task was to attend to face perception or to attend to spatial location of the objects. Thus, in the face-matching task, there was greater activation in the parvocellular dominated ventral pathway (occipitotemporal). Conversely, the locationmatching task produced greater activation bilaterally in the parietal lobes, which was along the magnocellular dominated dorsal pathway (occipitoparietal) [10-12]. For example, Corbetta et al. $[13,14]$ showed that regions pro- cessing either shape, color or velocity were selectively activated when attending to that aspect of a visual array. Similarly, Haxby et al. [12] found selective activation along the ventral and dorsal pathways when attending to face or location properties of the stimuli, respectively.

Most of the previous studies included young and healthy subjects. In the past, age-related changes in cortical blood flow activation during visual processing of faces and locations were investigated with a PET study [12]. fMRI as an alternative method for imaging of cognitive functions uses the blood oxygenation level-dependent (BOLD) contrast, which reflects both cerebral blood flow and oxygen extraction evoked by neuronal stimulation [13].

Therefore, we presume that any age-related change in brain anatomy, neuronal density, vasculature, metabolism, or neuronal responsitivity would influence the activation patterns detected with fMRI.

Thus, to investigate the age-dependent effects of visual function along both visual pathways, we developed two visual processing paradigms that activated preferentially either the ventral or dorsal pathway of the visual system in young or elderly healthy subjects. The hypothesis was that in elderly individuals compensatory processes would selectively involve one of the named visual pathways.

\section{Materials and Methods}

\section{Subjects}

The study included 34 healthy right-handed volunteers. The handiness was an important inclusion criterion to ensure the lateralization. The subjects were divided into two groups: 15 young subjects ( 9 females $/ 6$ males) with a mean age \pm standard deviation of $28 \pm 9$ years and 19 elderly subjects (11 female/8 males) with a mean age \pm standard deviation of $71 \pm 6$ years. The subjects were screened for conditions which precluded MRI scanning (e.g. pace maker, metals in body, pregnancy, claustrophobia) and for a history of neurological or psychiatric disease. The eyesight of the subjects was normal or corrected to normal. All subjects gave their written informed consent for the procedure. The Ethics Committee of the Medical Faculty of the Ludwig-Maximilian University approved the study.

\section{Paradigm}

Stimuli were generated by a DOS-based computer using the software VAAP and were projected with an LCD video projector (NEC) onto a translucent screen placed at the feet of the subject. The subject was able to see the screen by the use of a mirror system. The subjects had a response button in their right hand. The performance was documented as accuracy and reaction time. For the face-matching task, each item consisted of two simultaneously presented stimuli. An illustration is shown in figure 1. The subjects indicated whether the two displayed faces were identical by pressing the response button. For the location-matching task, the sub- 
a

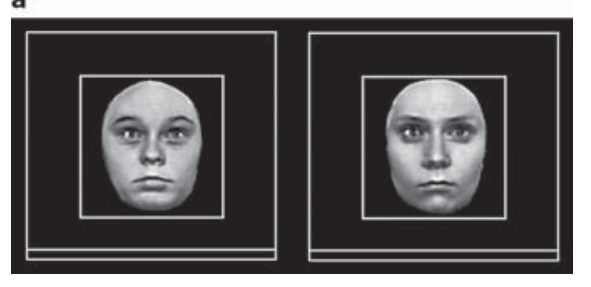

a

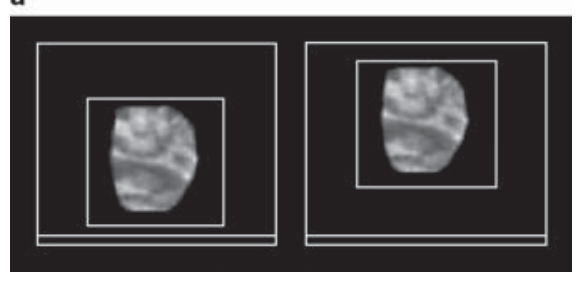

b

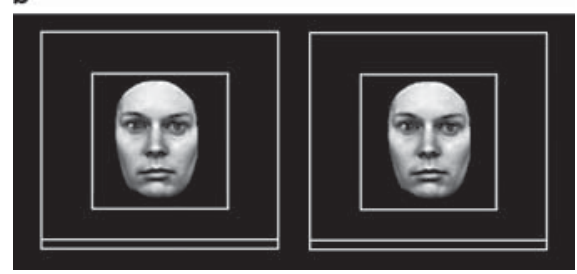

b

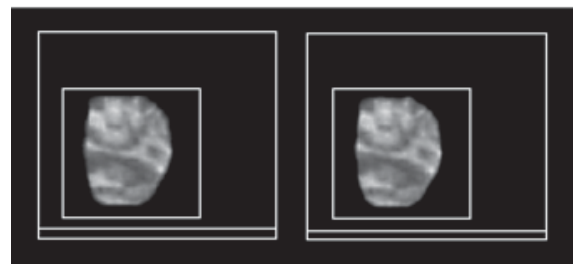

Fig. 2. Location-matching task: the individuals had to press the button when the relative positions of the scrambled faces in the boxes were identical. a Different positions of the scrambled faces. b Identical positions.

Fig. 1. Face-matching task: the individuals had to press the button when the presented b Identical shapes.

jects had to press the button when two simultaneously displayed objects (nonsense scrambled faces) had an identical position within two boxes presented on the screen (fig. 2). The sensomotoric control task consisted of stimuli with similar visual complexity as the face-matching task. The subjects had to press the button whenever a nonsense scrambled face appeared on the screen (fig. 3). The subjects were pretrained on the tasks before scanning.

For all tasks, each stimulus was presented on the screen for $2.8 \mathrm{~s}$ with an interstimulus interval of $0.318 \mathrm{~s}$. Each run consisted of 7 blocks alternating between control condition (4 blocks) and activation ( 3 blocks). Eight stimuli were presented per block. Each run included 69 frames with an interval of $3.6 \mathrm{~s}$ resulting in a total duration of $4.14 \mathrm{~min}$. A centered red fixation cross was presented for $14.4 \mathrm{~s}$ ( 4 frames) at the beginning and for $7.2 \mathrm{~s}$ ( 2 frames) at the end of each run. Before each block, a written instruction appeared for $7.2 \mathrm{~s}$ (2 frames). Each block had a duration of $25.2 \mathrm{~s}$ (7 frames). Each experiment started with the control condition.

\section{Imaging Procedure}

Imaging was performed with a 1.5-tesla MR scanner (Magnetom Vision, Siemens, Germany) using a standard head coil. Head movement was restricted by a vacuum positioning pillow and foam pads. The functional sequence was an interleaved $\mathrm{T}_{2}{ }^{{ }^{-}}$ weighted echoplanar sequence with 28 axial slices $(\mathrm{TE}=60 \mathrm{~ms}$, $\mathrm{TR}=3.6 \mathrm{~s}$, flip angle $=90^{\circ}$, slice thickness $=4 \mathrm{~mm}$, gap $=1 \mathrm{~mm}$, matrix $=64 \times 64$, pixel size $3.75 \times 3.75 \mathrm{~mm}$ ). In addition, we acquired structural images using a 3 -dimensional magnetization prepared rapid gradient echo (MPRAGE) sequence in sagittal orientation $\left(\mathrm{TE}=4.4 \mathrm{~ms}, \mathrm{TR}=11.4 \mathrm{~ms}\right.$, flip angle $=90^{\circ}, \mathrm{FOV}=270$ $\mathrm{mm}$, matrix $=224 \times 256$, effective thickness $=1.25 \mathrm{~mm}$ ) as well as an axial $\mathrm{T}_{1}$-weighted sequence $(\mathrm{TE}=620 \mathrm{~ms}$; $\mathrm{TR}=12 \mathrm{~ms}$, flip angle $=90^{\circ}$, slices $=28$, slice thickness $=4 \mathrm{~mm}$, gap $=1 \mathrm{~mm}$, $\mathrm{FOV}=240 \mathrm{~mm}$, matrix $=224 \times 256$ ).

\section{Statistical Analysis}

The data were analyzed using FSL (FMRIB Software Library available at www.Fmrib.oc.ac.uk/fsl) and AFNI (available at www. afni.nimh.nih.gov/afni/).

The initial step was to delete the first 4 volumes to eliminate the initial $\mathrm{T}_{1}$ magnetic transients. The remaining data were cor-

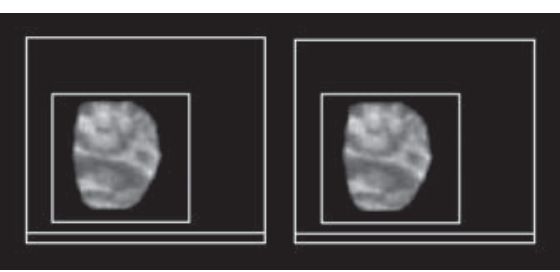

Fig. 3. Control condition (perception): the individuals had to press the button whenever the images appeared.

rected for timing differences between each slice using Fourier interpolation. Possible head movements between the volumes were corrected by aligning all volumes to a reference in the center of the run using automated image registration software (6-parameter rigid body) included in the FSL software package. The data were smoothed with a low-pass Gaussian filter (FWHM of $8 \mathrm{~mm}$ ) and high pass filtered with a cutoff of $1 / 100 \mathrm{~Hz}$.

Each run was analyzed using a fixed-effect general linear model. The model was composed of a regressor indicating the task of interest, a regressor for the instructions, the time derivatives of the two previous regressors and regressors for motion during the run. All models were convolved with a canonical hemodynamic response function. The statistical results were normalized to the Montreal Neurological Institute/International Consortium for Brain Mapping (MNI/ICBM) standard template. The location of the activation in the brain was done with reference to Talairach and Tournoux template. To convert the MNI/ICBM coordinates to the Talairach and Tournoux coordinates, we utilized a nonlinear transformation developed by M. Brett for transforming coordinate location between both stereotaxic spaces (http://www.mrc-cbu.cam.ac.uk/Imaging/mnispace.html).

The group statistical analyses were based on a random effects model with a voxel-wise threshold of $Z=2.33(\mathrm{p}<0.01)$ and each cluster was corrected for multiple comparisons at the $\mathrm{p}<0.05$ level. 

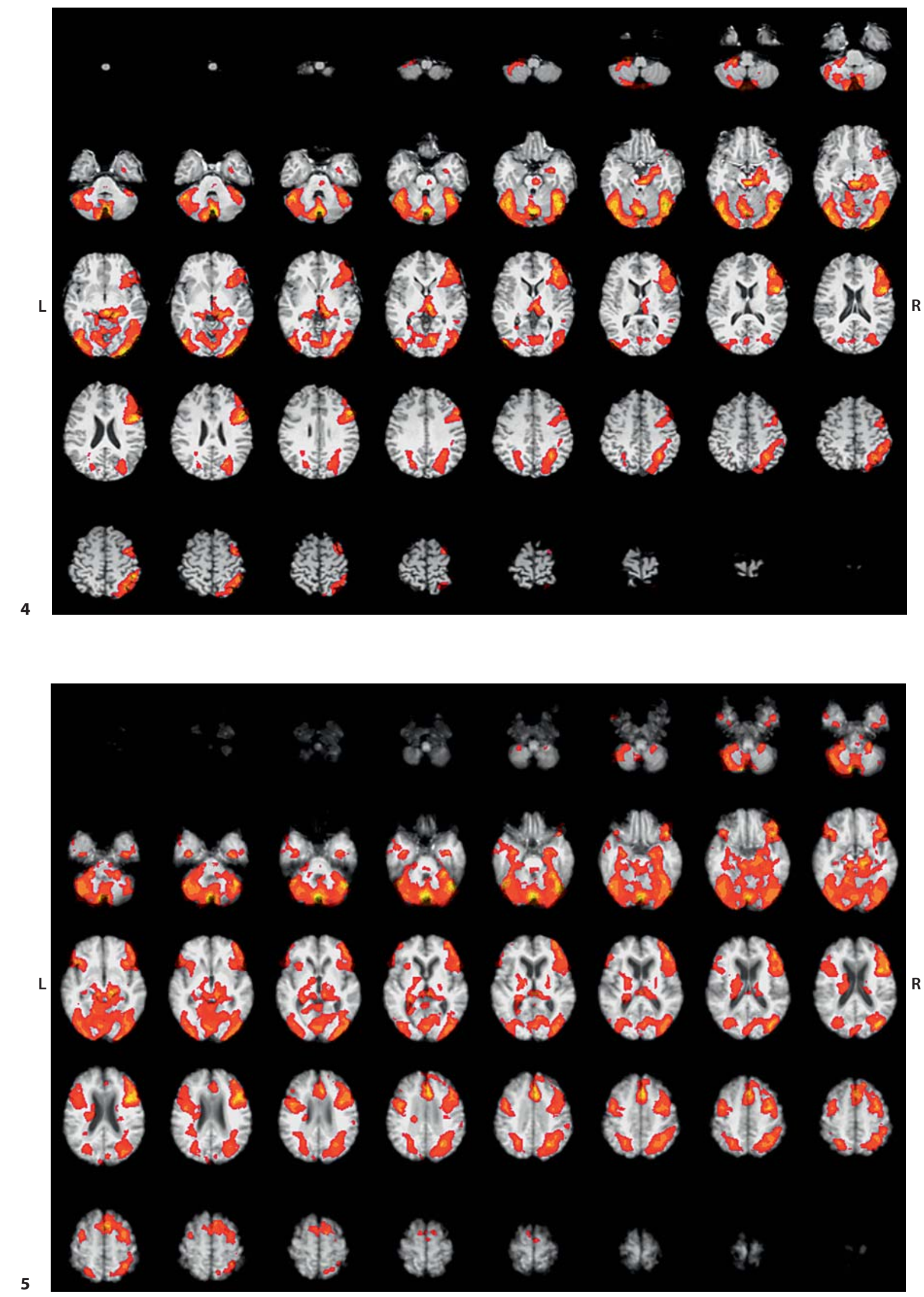
The structural images were edited of the non-brain tissue using a brain extraction tool (BET). The EPI images were coregistered to the axial 28 -slice $\mathrm{T}_{1}$ scan with a 7-parameter rigid body model. Then the $T_{1}$-weighted scan was registered to the MPRAGE sequence, and the MPRAGE images were registered to the MNI/ ICBM standard template (12 parameters).

\section{Results}

\section{Behavioral Performance}

The mean reaction times and the response accuracies of the age-related groups were evaluated for both paradigms. In the face-matching task, the mean reaction time of the younger subjects was $1.1 \mathrm{~s}$ (range: $0.32 \mathrm{~s}$ ) versus $1.5 \mathrm{~s}$ (range: $0.45 \mathrm{~s}$ ) in the group of elderly subjects. In the location-matching task, the mean reaction time of the younger volunteers was $1.0 \mathrm{~s}$ (range: $0.36 \mathrm{~s}$ ) versus $1.4 \mathrm{~s}$ (range: $0.40 \mathrm{~s}$ ) in the elderly subjects. Considering both paradigms, the differences of the reaction times were not statistically significant between the age-related groups (appropriate $t$ test, $\mathrm{p}>0.005$ ). The mean response accuracy in face-matching of the younger subjects was $93.1 \%$ (range: $7 \%$ ) and of the elderly subjects $92.9 \%$ (range: 12\%). In location matching, the young subjects responded in $94.1 \%$ of the cases (range: 10\%) correctly, the elderly persons in $94.9 \%$ (range: 9.8\%). The response accuracies were not significantly different between the groups.

\section{Activation Patterns}

\section{Face-Matching Task}

The mean activation patterns during face matching of the young and elderly group are illustrated in figures 4 and $5(Z>4.0)$.

Corresponding Activation Patterns in Young and Elderly Individuals Using the Face-Matching Task

Both elderly and young subjects presented predominantly right-sided activations. During face matching, both groups showed activated areas in the right as well as in the left occipital lobe. Activations were detected in the inferior and middle occipital gyrus, in the fusiform gyrus

Fig. 4. Face-matching task: activation pattern in the group of young and healthy subjects $(Z=2.33$; $\mathrm{p}<0.01)$.

Fig. 5. Face-matching task: activation pattern in the group of elderly and healthy subjects $(Z=2.33$; $\mathrm{p}<0.01)$.

Age-Dependent Differences in Human

Brain Activity and in the lingual gyrus. In the parietal lobes, both groups had bilateral activations particularly in the inferior parietal lobulus.

In the temporal lobes, we found right-hemispheric activations in young and elderly subjects.

Differences between Young and Elderly Individuals in the Face-Matching Task

Elderly individuals had significantly higher peaks of activation in the left and right fusiform gyrus as well as in the left lingual gyrus. Elderly subjects presented additional significant activations in the left temporal lobe (medial temporal gyrus; inferior temporal gyrus and parahippocampal gyrus). The elderly subjects had a small increase of signal intensities in the left postcentral gyrus and the left inferior parietal lobulus. Elderly individuals presented additional signal intensity increases in the left cerebellum and in parts of the left basal ganglia. Regarding the frontal lobes, young individuals demonstrated unilateral activation of right-hemispheric medial and inferior frontal gyrus. In elderly subjects, we found bilateral activation in the medial and inferior frontal gyrus.

The differences of the mean activation patterns during face matching between the young and elderly group (contrast: elderly - young) are illustrated in figure 6. Table 1 shows the peaks of significantly higher activations $(Z>$ 4.5 ) in elderly than in young subjects during the facematching task. In contrast, young subjects demonstrated no additional activations compared with elderly individuals. There was no significant difference in the respective group analysis (contrast: young - elderly).

\section{Location-Matching Task}

The mean activation patterns during location matching of the young and elderly groups are illustrated in figures 7 and 8 . The main activation peaks $(Z>4)$ with their respective coordinates in the Talairach and Tournoux coordinate system and Brodmann areas are shown in tables 2 and 3.

Corresponding Activation Patterns in Young and Elderly Individuals Using the Location-Matching Task

The local maxima of activation during the locationmatching task in young and elderly healthy individuals were located mainly in the parietal lobus. Activation was detected bilaterally in the inferior parietal lobulus with predominance of the right hemisphere. Further activations were found in the right frontal lobe. In both groups, the local maxima of activation were noted in the right inferior and middle frontal gyrus.

Dement Geriatr Cogn Disord 2007;24:235-246 
Table 1. Peaks of significantly higher activation in elderly than in young subjects during the face-matching task

\begin{tabular}{|c|c|c|c|c|c|c|c|}
\hline & $\mathrm{Z}$ & $\mathrm{x}$ & $\mathrm{y}$ & $\mathrm{z}$ & Region & Brodmann & Hemisphere \\
\hline \multirow[t]{5}{*}{ Frontal lobe } & 2.6 & -24 & -76 & $2-6$ & gyrus frontalis medius & 6 & right \\
\hline & 3.7 & 26 & 20 & 41 & gyrus frontalis medius & 8 & left \\
\hline & 4.1 & 28 & 2 & 31 & gyrus frontalis inferior & 44 & left \\
\hline & 4.0 & 42 & $2-1$ & 24 & gyrus frontalis inferior & 44 & left \\
\hline & 3.8 & 22 & -18 & 34 & gyrus cinguli & 24 & left \\
\hline \multirow[t]{2}{*}{ Parietal lobe } & 3.8 & 50 & -14 & 27 & gyrus postcentralis & 3 & left \\
\hline & 3.6 & 36 & -28 & 31 & lobus parietalis inferior & 40 & left \\
\hline \multirow[t]{8}{*}{ Temporal lobe } & 3.3 & 30 & -10 & -37 & gyrus temporalis inferior & 20 & left \\
\hline & 3.9 & 52 & -16 & -18 & gyrus temporalis inferior & 21 & left \\
\hline & 3.7 & 42 & -22 & $2-4$ & gyrus temporalis medius & 21 & left \\
\hline & 3.6 & 40 & -12 & -13 & gyrus temporalis medius & 21 & left \\
\hline & 3.4 & 55 & -36 & -13 & gyrus temporalis medius & 21 & left \\
\hline & 3.2 & 44 & -33 & $2-3$ & gyrus temporalis medius & 21 & left \\
\hline & 3.0 & 61 & 5 & -20 & gyrus temporalis medius & 21 & left \\
\hline & 3.6 & 26 & -32 & -14 & gyrus parahippocampalis & 36 & left \\
\hline \multirow[t]{3}{*}{ Occipital lobe } & 3.2 & 44 & -32 & -15 & gyrus fusiforme & 20 & right \\
\hline & 3.9 & 59 & -19 & -24 & gyrus fusiforme & 20 & left \\
\hline & 3.8 & -20 & -95 & -31 & gyrus lingualis & 19 & left \\
\hline \multirow[t]{4}{*}{ Basal ganglia } & 3.7 & 18 & -11 & 17 & thalamus & & left \\
\hline & 3.6 & 32 & -21 & 3 & claustrum & & left \\
\hline & 3.7 & 10 & 2 & 4 & globus pallidus & & left \\
\hline & 3.7 & 24 & -19 & 18 & nucleus caudatus & & left \\
\hline \multirow[t]{6}{*}{ Cerebellum } & 4.2 & $2-2$ & -80 & -15 & cerebellum & & right \\
\hline & 3.8 & -10 & -81 & -20 & cerebellum & & left \\
\hline & 3.9 & 26 & -87 & -34 & cerebellum & & left \\
\hline & 3.4 & 46 & -79 & -28 & cerebellum & & left \\
\hline & 3.3 & 28 & -41 & -35 & cerebellum & & left \\
\hline & 2.9 & 38 & -56 & -38 & cerebellum & & left \\
\hline
\end{tabular}

Both groups also demonstrated bilateral activations in the occipital lobes, especially in the inferior and medial occipital gyrus, in the precuneus, cuneus and the fusiform gyrus.

Both age-dependent groups showed bilateral activations in the cerebellum.

Differences between Young and Elderly Individuals in the Location-Matching Task

Only minor activation was found in the right medial and inferior temporal gyrus as well as in the hippocampus in young subjects. The differences of the mean activation patterns (contrasts: young - elderly; elderly young) were analyzed, but there were no statistically significant differences between both age groups in the location-matching task.

\section{Discussion}

Much of the understanding of the primate extrastriate cortex has come from combined anatomical, physiological, and behavioral studies of the monkey brain. The functional dissociation of human extrastriate cortical processing streams for the perception of face identification and location was investigated in 1994 by Haxby et al. [12] using rCBF in a PET study. They demonstrated that face matching was associated with selective $\mathrm{rCBF}$ in-

Fig. 6. Face-matching task: difference between elderly and young subjects (contrast: elderly - young; $\mathrm{Z}=2.33$; $\mathrm{p}<0.01$ ).

Fig. 7. Location-matching task: activation pattern in the group of young and healthy subjects $(Z=2.33 ; \mathrm{p}<0.01)$. 

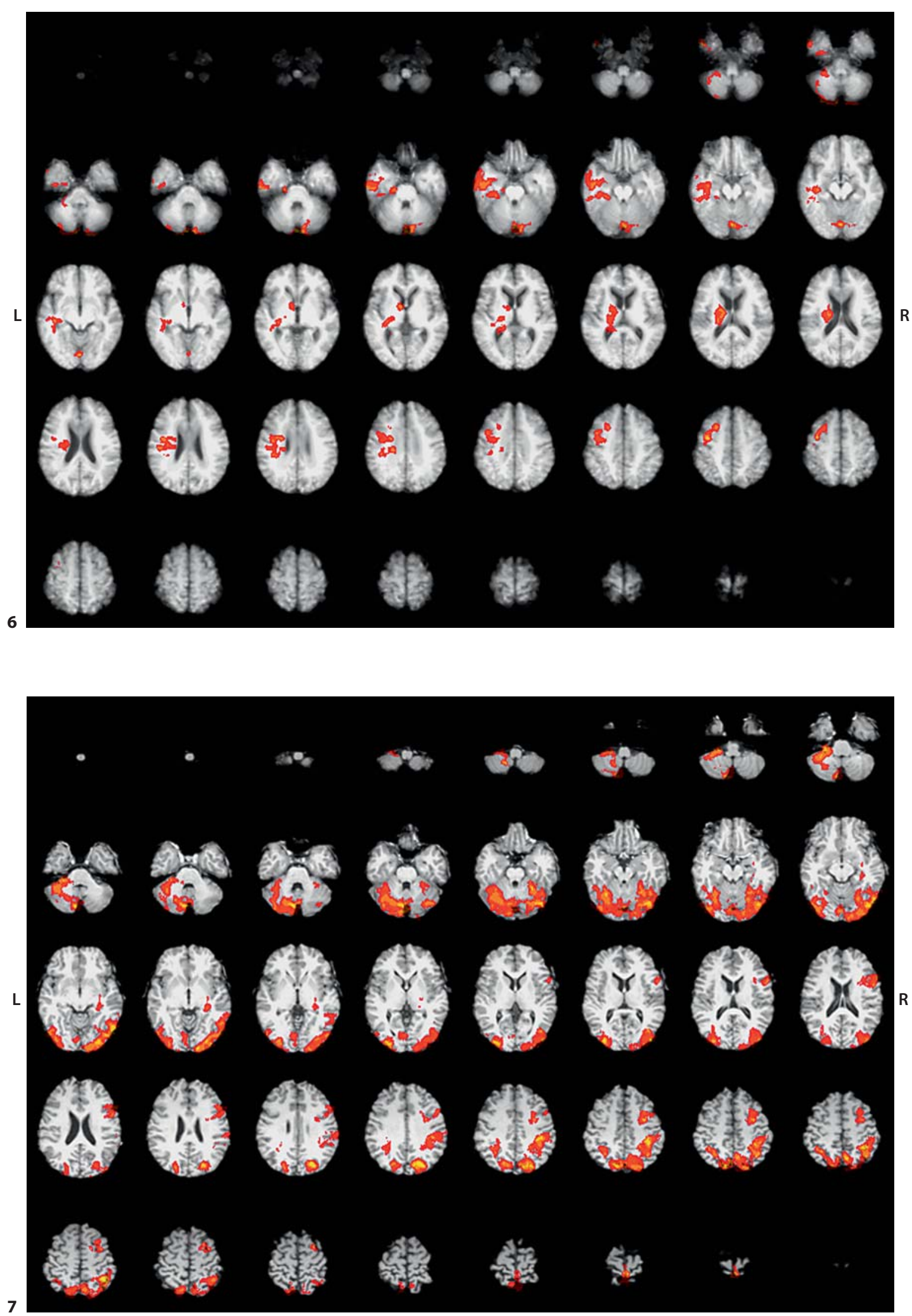


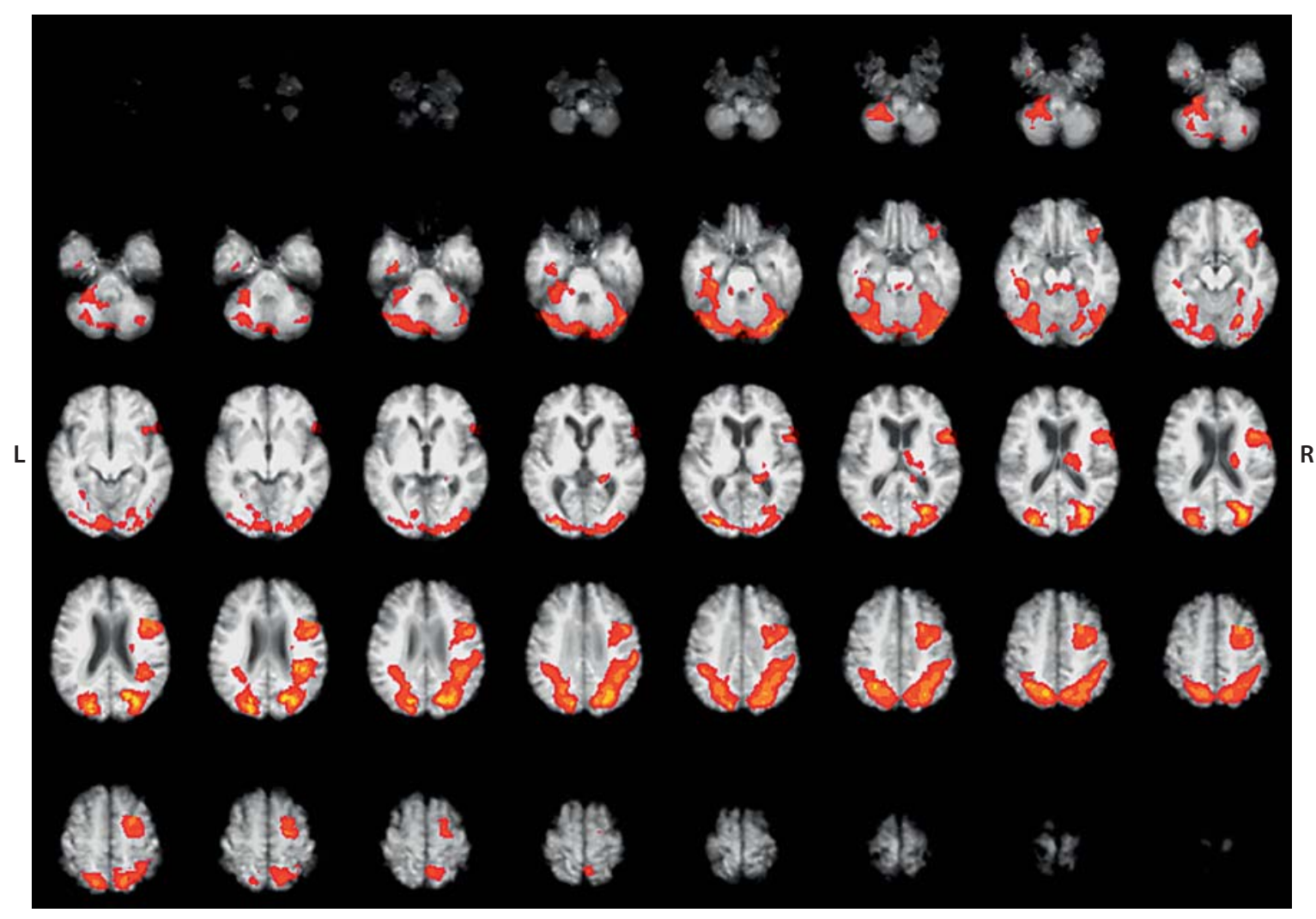

Fig. 8. Location-matching task: activation pattern in the group of elderly and healthy subjects $(Z=2.33$; $\mathrm{p}<0.01)$.

creases in the fusiform gyrus, in the occipital and occipitotemporal cortex bilaterally and in a right prefrontal area in the inferior frontal gyrus. Location matching was associated with selective rCBF increases in the dorsal occipital, superior parietal, and intraparietal sulcus cortex bilaterally [14]. Imaging studies in visual attention have shown that healthy control subjects attending to visuospatial information activated the occipitoparietal path of the visual system while in a visual recognition task they activated the occipitotemporal path of the visual systems $[10,14-16]$.

We could demonstrate that young and elderly healthy subjects showed activation in the occipitotemporal as well as in the occipitoparietal pathways for the face- and location-matching tasks, respectively. Thus, in the facematching task, there was a predominance of activation in the occipitotemporal pathway. The location-matching task, on the other hand, led to predominant activations in the occipitoparietal pathway. The results obtained are consistent with the results of Corbetta et al. [17] and Shulman et al. [18], as well as with the results of Haxby et al.
$[10,12]$. They showed that selective attention to a specific aspect of a stimulus will selectively increase activation for the network that processes that specific type of information. In 1991, Corbetta et al. [17] reported that regions processing either shape, color or velocity are selectively activated when attending to that aspect of a visual array. Similarly, Haxby et al. $[10,12]$ found selective activation along the ventral and dorsal pathways when attending to object or location properties of the stimuli, respectively. Thus, the present tasks selectively activate the ventral and dorsal pathways of the visual system $[10,14,17,18]$.

\section{Differences in Activation Patterns of Young versus \\ Elderly Subjects}

Age-related changes have been reported in the cerebral vasculature. Anatomical studies demonstrated thickening of the vascular basement membrane and thinning the endothelium in elderly individuals [19]. Less well established are the effects of aging upon cerebral blood flow and metabolism: some authors reported age-related declines of cerebral blood flow [20]. Some studies using 
Table 2. Local maxima of activation during the location-matching task in young healthy subjects

\begin{tabular}{|c|c|c|c|c|c|c|c|}
\hline & $\mathrm{Z}$ & $\mathrm{x}$ & $\mathrm{y}$ & $\mathrm{z}$ & Region & Brodmann & Hemisphere \\
\hline \multirow[t]{6}{*}{ Frontal lobe } & 4.8 & -36 & 4 & 50 & gyrus frontalis medius & 6 & right \\
\hline & 4.8 & -24 & 9 & 57 & gyrus frontalis medius & 6 & right \\
\hline & 4.6 & -32 & 2 & 40 & gyrus frontalis medius & 9 & right \\
\hline & 4.6 & -32 & 46 & -11 & gyrus frontalis medius & 11 & right \\
\hline & 4.6 & -44 & 43 & 2 & gyrus frontalis inferior & 46 & right \\
\hline & 4.5 & -48 & 13 & 33 & gyrus frontalis inferior & 44 & right \\
\hline \multirow[t]{6}{*}{ Parietal lobe } & 5.2 & -36 & -56 & 54 & lobus parietalis superior & 7 & right \\
\hline & 5.3 & -40 & -37 & 42 & lobus parietalis inferior & 40 & right \\
\hline & 4.9 & -46 & -38 & 52 & lobus parietalis inferior & 40 & right \\
\hline & 4.5 & -44 & -50 & 43 & lobus parietalis inferior & 40 & right \\
\hline & 4.5 & 24 & -64 & 51 & lobus parietalis superior & 7 & left \\
\hline & 4.6 & 32 & -56 & 47 & lobus parietalis inferior & 40 & left \\
\hline \multirow[t]{3}{*}{ Temporal lobe } & 5.5 & -48 & -55 & -2 & gyrus temporalis medius & 37 & right \\
\hline & 4.4 & -57 & -49 & -13 & gyrus temporalis inf. & 37 & right \\
\hline & 4.3 & -24 & -33 & -3 & hippocampus & & right \\
\hline \multirow[t]{18}{*}{ Occipital lobe } & 4.8 & -20 & -75 & 46 & precuneus & 7 & right \\
\hline & 4.7 & -10 & -60 & 51 & precuneus & 7 & right \\
\hline & 5.2 & -14 & -95 & 3 & cuneus & 17 & right \\
\hline & 5.0 & -22 & -84 & -13 & gyrus fusiforme & 18 & right \\
\hline & 5.7 & -28 & -88 & -2 & gyrus occipitalis inferior & 18 & right \\
\hline & 4.6 & -18 & -89 & 12 & gyrus occipitalis medius & 18 & right \\
\hline & 5.4 & -42 & -74 & -3 & gyrus occipitalis medius & 19 & right \\
\hline & 5.1 & -34 & -81 & 13 & gyrus occipitalis medius & 19 & right \\
\hline & 4.9 & -40 & -81 & 23 & gyrus occipitalis medius & 19 & right \\
\hline & 5.0 & -14 & -90 & 23 & cuneus & 19 & right \\
\hline & 5.0 & -24 & -68 & 37 & precuneus & 19 & right \\
\hline & 4.5 & 14 & -68 & 40 & precuneus & 7 & left \\
\hline & 4.5 & 10 & -61 & 58 & precuneus & 7 & left \\
\hline & 4.6 & 22 & -77 & 17 & cuneus & 18 & left \\
\hline & 5.3 & 32 & -89 & 12 & gyrus occipitalis medius & 18 & left \\
\hline & 4.7 & 22 & -90 & 27 & cuneus & 19 & left \\
\hline & 4.5 & 34 & -80 & -4 & gyrus occipitalis inferior & 19 & left \\
\hline & 4.6 & 22 & -78 & 32 & precuneus & 19 & left \\
\hline \multirow[t]{5}{*}{ Cerebellum } & 5.3 & -40 & -71 & -18 & cerebellum & & right \\
\hline & 4.9 & -24 & -39 & -40 & cerebellum & & right \\
\hline & 5.1 & 32 & -59 & -16 & cerebellum & & left \\
\hline & 4.6 & 34 & -41 & -35 & cerebellum & & left \\
\hline & 4.5 & 22 & -35 & -40 & cerebellum & & left \\
\hline
\end{tabular}

FDG-PET suggested that age-related changes in resting brain metabolism may differ across brain regions with significant changes occurring in frontal and visual cortex [21]. Functional PET studies demonstrated widespread age-related changes in the activation patterns evoked by cognitive challenges [22-24].

Few studies, however, have investigated the effects of aging upon fMRI-derived measurements. Taoka et al.
$[24,25]$ measured the temporal characteristics of fMRI activation in motor cortex during a hand-squeezing task. Using a regression technique across a wide range of subject ages (20-76 years), they found that there were age-related changes in the risetime of the fMRI signal. This slowing of signal rise in elderly subjects was attributed to vascular effects, including stiffening of the arterial wall. Age-related differences have also been reported for a pho- 
Table 3. Local maxima of activation during the location-matching task in elderly healthy subjects

\begin{tabular}{|c|c|c|c|c|c|c|c|}
\hline & $\mathrm{Z}$ & $\mathrm{x}$ & $\mathrm{y}$ & $\mathrm{z}$ & Region & Brodmann & Hemisphere \\
\hline \multirow{5}{*}{ Frontal lobe } & 4.5 & -32 & -2 & 39 & gyrus frontalis medius & 9 & right \\
\hline & 4.5 & -28 & 12 & 47 & gyrus frontalis medius & 8 & right \\
\hline & 4.2 & -46 & 15 & 23 & gyrus frontalis inferior & 44 & right \\
\hline & 4.2 & -48 & 5 & 26 & gyrus frontalis inferior & 6 & right \\
\hline & 4.1 & -26 & -67 & -8 & gyrus frontalis inferior & 19 & right \\
\hline \multirow[t]{6}{*}{ Parietal lobe } & 4.3 & -57 & -22 & 34 & gyrus postcentralis & 2 & right \\
\hline & 4.7 & -40 & -38 & 28 & lobus parietalis inferior & 40 & right \\
\hline & 4.3 & -40 & -43 & 43 & lobus parietalis inferior & 40 & right \\
\hline & 4.0 & -52 & 14 & 12 & lobus parietalis inferior & 44 & right \\
\hline & 4.7 & 36 & -52 & 45 & lobus parietalis inferior & 40 & left \\
\hline & 4.7 & 28 & -54 & 45 & lobus parietalis inferior & 40 & left \\
\hline \multirow{15}{*}{ Occipital lobe } & 4.3 & -16 & -59 & 55 & precuneus & 7 & right \\
\hline & 4.2 & -20 & -5 & 56 & cuneus & 18 & right \\
\hline & 4.7 & -28 & -90 & -9 & gyrus occipitalis inferior & 18 & right \\
\hline & 5.9 & -20 & -67 & 27 & precuneus & 18 & right \\
\hline & 5.8 & -30 & -73 & 24 & precuneus & 18 & right \\
\hline & 5.0 & -24 & -70 & 37 & precuneus & 19 & right \\
\hline & 4.1 & -20 & -35 & 7 & gyrus fusiforme & & right \\
\hline & 4.9 & 14 & -62 & 47 & precuneus & 7 & left \\
\hline & 4.5 & 22 & -53 & 34 & precuneus & 7 & left \\
\hline & 5.2 & 24 & -76 & 28 & gyrus occipitalis & 19 & left \\
\hline & 4.8 & 30 & -83 & 13 & gyrus occipitalis medius & 19 & left \\
\hline & 4.1 & 36 & -82 & -6 & gyrus occipitalis medius & 19 & left \\
\hline & 5.0 & 16 & -74 & 37 & precuneus & 19 & left \\
\hline & 4.1 & 38 & -13 & -25 & gyrus fusiforme & 20 & left \\
\hline & 4.2 & 40 & -28 & -14 & gyrus fusiforme & 36 & left \\
\hline \multirow[t]{6}{*}{ Cerebellum } & 4.8 & -40 & -78 & -15 & cerebellum & & right \\
\hline & 4.7 & -40 & -71 & -17 & cerebellum & & right \\
\hline & 4.4 & -24 & -77 & -15 & cerebellum & & right \\
\hline & 4.2 & 28 & -71 & -12 & cerebellum & & left \\
\hline & 4.0 & 24 & -35 & -35 & cerebellum & & left \\
\hline & 4.0 & 4 & -80 & -16 & vermis & & left \\
\hline
\end{tabular}

tic stimulation task using fMRI, such that signal amplitude was decreased in elderly subjects, but the spatial extent of activation did not differ from that of young subjects [26]. D'Esposito et al. [26] investigated the characteristics of the fMRI-derived hemodynamic response (HDR) evoked in a motor task in groups of young and elderly subjects. Young subjects exhibited higher signal-to-noise ratios than did elderly subjects. However, there were no significant differences between the groups in either the shape or within-group variability of the HDR. These results suggest that fMRI imaging analyses can be profitably conducted on elderly subjects [27].
Face-Matching Task

In the present study, young and elderly individuals showed a similar activation pattern of the occipitotemporal pathway. However, additional local activation could be found in elderly subjects in the left temporal lobe, in the inferior, middle and superior frontal gyrus, as well as in the anterior cingulate. Elderly subjects presented bilateral frontal and temporal activation in contrast to the young subjects who demonstrated unilateral right-hemispheric activation in the named regions.

Location-Matching Task

In the location-matching task, main activations were located in the occipitoparietal pathway and in the right 
prefrontal cortex. We found no significant differences between both age groups.

In the present study, both tasks were set up with a relatively low difficulty level. Therefore, the behavioral performance was not significantly different in young and in elderly subjects.

We used very easy tasks which should enable the patients to perform the tasks comparably to the healthy subjects.

Only the face-matching task induced a recruitment of additional brain regions in elderly subjects in comparison to the young individuals. One cause could be that the complexity of the face-matching task may be more extensive than the complexity of the location-matching task. If the task difficulty will be the reason, we have to discuss whether the ventral visual pathways could be more sensitive for age-dependent degeneration processes leading to earlier compensation mechanisms than the dorsal visual pathways. To better understand the changes occurring within the visual cortex, expanding this study by investigating the increases in task difficulty may further illuminate how the compensatory process changes.

The present results using the visual function tasks suggest that even when behavioral performance between groups does not differ, the neural systems that support performance may not be the same. The differences in activation pattern using the face-matching task that we found may happen when the optimal or ideal network (as defined by the young subjects) is compromised by age.

It is well known that the brain hemispheres are anatomically and functionally asymmetric. There is evidence that these asymmetries are affected by conditions that alter the anatomical and functional integrity of the brain, such as brain damage and aging. Two models have recently been discussed: (a) the right hemi-aging model and (b) the hemispheric asymmetry reduction in old adults (HAROLD) model. The right hemi-aging hypothesis states that age-related cognitive declines affect functions attributed to the right hemisphere to a greater degree than those associated with the left hemisphere. As mentioned earlier, the HAROLD model states that, under similar conditions, prefrontal cortex activity tends to be less lateralized in older adults than in younger adults. The hypotheses are based on several neurofunctional imaging studies across such domains as perception, episodic, semantic, and working memory, but do not take into account structural changes $[28,29]$.

On the other hand, in a PET study on face encoding [31], age-related asymmetry reductions were found not only in the prefrontal cortex but also in temporal and pa- rietal regions. Also, in a PET study on face perception [31], positive correlations between temporoparietal activity and memory performance were found in the left hemisphere for young adults but bilaterally for old adults. During a source memory task, young adults and low-performing older adults recruited similar right prefrontal cortex regions, whereas high-performing older adults engaged prefrontal cortex regions bilaterally. The results of Cabeza et al. [30] suggest that low-performing older adults recruit a similar network of brain regions as young adults but use them inefficiently, whereas high-performing older adults counteract age-related neural decline by reorganizing brain functions [31]. The behavioral data in our groups were not significantly different. We saw no statistically relevant range of the behavioral data within the groups.

If age-related asymmetry reductions have a neural origin, then a good understanding of the neural mechanisms underlying these reductions may eventually lead to the development of drugs and other therapies.

In summary, we support the hypothesis of Cabeza et al. [31], who reported of task-independent and task-specific age effects recently. Their results showed that older adults demonstrated weaker occipital activity and stronger prefrontal and parietal activity than younger adults during working memory and visual attention tasks. They found bilateral activations, especially prefrontal and parietal, correlating with an increased age of the subjects.

\section{Conclusion}

The difference in activation pattern using the facematching task that we found may happen when the optimal or ideal network (as defined by the young subjects) is compromised by age more than the activation pattern using the location-matching task.

References

1 Herholz K, Salmon E, Perani D, Baron JC, Holthoff V, Frolich L, Schonknecht P, Ito K, Mielke R, Kalbe E, Zundorf G, Delbeuck X, Pelati O, Anchisi D, Fazio F, Kerrouche N, Desgranges B, Eustache F, Beuthien-Baumann B, Menzel C, Schroder J, Kato T, Arahata Y, Henze M, Heiss WD: Discrimination between Alzheimer dementia and controls by automated analysis of multicenter FDG PET. Neuroimage 2002;17:302-316.

2 Kessler J, Herholz K, Grond M, Heiss WD: Impaired metabolic activation in Alzheimer's disease: a PET study during continuous visual recognition. Neuropsychologia 1991;29:229-243. 
3 Petrella JR, Coleman RE, Doraiswamy PM: Neuroimaging and early diagnosis of Alzheimer disease: a look to the future. Radiology 2003;226:315-336.

4 Haxby JV, Grady CL, Horowitz B, Salerno J, Ungerleider LG, Mishkin M, Shapiro MB: Dissociation of object and spatial visual processing pathways in human extrastriate cortex; in Gulays B, Otooson D, Roland PE (eds): Functional Organization of the Human Visual Cortex. Oxford, Pergamon, 1993, pp 329-340.

5 Sergent J, Ohta S, MacDonald B: Functional neuroanatomy of face and object processing. Brain 1992;115:15-36.

6 Kanwisher N, Wojciulik E: Visual attention: insights from brain imaging. Nat Rev Neurosci 2000;1:91-100.

7 Haxby JV, Hoffman EA, Gobbini MI: The distributed human neural system for face perception. Trends Cogn Sci 2000;4:223233.

8 Kanwisher N, McDermott J, Chun MM: The fusiform face area: a module in human extrastriate cortex specialized for face perception. J Neurosci 1997;17:4302-4311.

9 Halgren E, Dale AM, Sereno MI, Tootell RB, Marinkovic K, Rosen BR: Location of human face-selective cortex with respect to retinotopic areas. Hum Brain Mapp 1999;7:29-37.

10 Haxby JV, Grady CL, Horwitz B, Ungerleider LG, Mishkin M, Carson RE, Herscovitch P, Schapiro MB, Rapoport SI: Dissociation of object and spatial visual processing pathways in human extrastriate cortex. Proc Natl Acad Sci USA 1991;88:1621-1625.

11 Sergent J, Ohta S, MacDonald B: Functional neuroanatomy of face and object processing. A positron emission tomography study. Brain 1992;115:15-36.

12 Haxby JV, Horwitz B, Ungerleider LG, Maisog JM, Pietrini P, Grady CL: The functional organization of human extrastriate cortex: a PET-rCBF study of selective attention to faces and locations. J Neurosci 1994;14:6336-6353.
13 Corbetta M, Miezin FM, Dobmeyer S, Shulman GL, Petersen SE: Selective and divided attention during visual discriminations of shape, color, and speed: functional anatomy by positron emission tomography. J Neurosci 1991;11:2383-2402.

14 Corbetta M, Miezin FM, Dobmeyer S, Shulman GL, Petersen SE: Attentional modulation of neural processing of shape, color, and velocity in humans. Science 1990;248:15561559.

15 Grady CL, Maisog JM, Horwitz B, Ungerleider LG, Mentis MJ, Salerno JA, Pietrini P, Wagner E, Haxby JV: Age-related changes in cortical blood flow activation during visual processing of faces and location. J Neurosci 1994; 14:1450-1462.

16 Buxton RB, Wong EC, Frank LR: Dynamics of blood flow and oxygenation changes during brain activation: the balloon model. Magn Reson Med 1998;39:855-864.

17 Corbetta M, Miezin FM, Dobmeyer S, Shulman GL, Petersen SE: Selective and divided attention during visual discriminations of shape, color, and speed: functional anatomy by positron emission tomography. J Neurosci 1991;11:2383-2402.

18 Shulman GL, Ollinger JM, Akbudak E, Conturo TE, Snyder AZ, Petersen SE, Corbetta $\mathrm{M}$ : Areas involved in encoding and applying directional expectations to moving objects. J Neurosci 1999;19:9480-9496.

19 Kalaria RN: Cerebral vessels in ageing and Alzheimer's disease. Pharmacol Ther 1996; 72:193-214.

20 Goldstein S, Reivich M: Cerebral blood flow and metabolism in aging and dementia. Clin Neuropharmacol 1991;14(suppl 1):S34-S44.

21 Loessner A, Alavi A, Lewandrowski KU, Mozley D, Souder E, Gur RE: Regional cerebral function determined by FDG-PET in healthy volunteers: normal patterns and changes with age. J Nucl Med 1995;36:1141-1149.

22 Madden DJ, Turkington TG, Coleman RE, Provenzale JM, DeGrado TR, Hoffman JM: Adult age differences in regional cerebral blood flow during visual world identification: evidence from $\mathrm{H}_{2}{ }^{15} \mathrm{O}$ PET. Neuroimage 1996;3:127-142.
23 Madden DJ, Gottlob LR, Denny LL, Turkington TG, Provenzale JM, Hawk TC, Coleman RE: Aging and recognition memory: changes in regional cerebral blood flow associated with components of reaction time distributions. J Cogn Neurosci 1999;11:511520 .

24 Taoka T, Iwasaki S, Uchida H, Fukusumi A, Nakagawa H, Kichikawa K, Takayama K, Yoshioka T, Takewa M, Ohishi H: Age correlation of the time lag in signal change on EPIfMRI. J Comput Assist Tomogr 1998;22: 514-517.

25 Ross MH, Yurgelun-Todd DA, Renshaw PF, Maas LC, Mendelson JH, Mello NK, Cohen BM, Levin JM: Age-related reduction in functional MRI response to photic stimulation. Neurology 1997;48:173-176.

26 D’Esposito M, Zarahn E, Aguirre GK, Rypma B: The effect of normal aging on the coupling of neural activity to the bold hemodynamic response. Neuroimage 1999;10:6-14.

27 Grady CL, Bernstein LJ, Beig S, Siegenthaler AL: The effects of encoding task on age-related differences in the functional neuroanatomy of face memory. Psychol Aging 2002;17:7-23.

28 Dolcos F, Rice HJ, Cabeza R: Hemispheric asymmetry and aging: right hemisphere decline or asymmetry reduction. Neurosci Biobehav Rev 2002;26:819-825.

29 Grady CL: Functional brain imaging and age-related changes in cognition. Biol Psychol 2000;54:259-281.

30 Cabeza R, Anderson ND, Locantore JK, McIntosh AR: Aging gracefully: compensatory brain activity in high-performing older adults. Neuroimage 2002;17:1394-1402.

31 Cabeza R, Daselaar SM, Dolcos F, Prince SE, Budde M, Nyberg L: Task-independent and task-specific age effects on brain activity during working memory, visual attention and episodic retrieval. Cereb Cortex 2004; $14: 364-375$. 